\title{
Os últimos intelectuais de Russell Jacoby: um convite ao debate
}

JACOBY, Russell. Os últimos intelectuais: a cultura americana na era da academia. Trad. Magda Lopes. São Paulo: Trajetória Cultural: Edusp, 1990.

Rafael Pereira da Silva*

Em meio à última greve nas Instituições Federais de ensino, a leitura de Os últimos intelectuais: a cultura americana na era da Academia, levanta um debate franco sobre o papel das universidades brasileiras, de seus professores e de sua bandeira: ensino, pesquisa, extensão. Esgotado no Brasil e pouco conhecido, o livro de Russel Jacoby, um professor exmilitante de esquerda apresenta uma crítica sobre o papel do intelectual frente aos problemas do seu tempo. Foca-se na área das ciências humanas e da literatura estendendo-se um pouco ao jornalismo e aos contextos do antes e do pós-guerra nos Estados Unidos, momento da expansão dos campi por todo o país. O autor defende a tese de que naquele país o intelectual público desapareceu completamente, não deixando ninguém no seu lugar, exceto um punhado de professores universitários tímidos, dominados por um jargão peculiar nos quais ninguém na sociedade prestava muita atenção, independentemente, se conservadores ou esquerdistas. Além desse trabalho, o único prublicado no Brasil, Jacoby é autor de Social Amnesia (1975), The dialetc of Defeat (1981) e The Repression of Psychoanalysis (1983).

O título por si só vale um comentário. “Últimos” na sua concepção apresenta um paradoxo: expõe o fim dos intelectuais públicos que buscavam espaço na imprensa e em outros veículos de informação, cuja linguagem, estilo e crítica radical pressupunha um leitor educado, amplo e sedento por debates, ao mesmo tempo em que apresenta os "últimos" como “novos”, voltados para si mesmos, para dentro dos muros universitários.

Independente da tomada de posição nos quadros do atual movimento, é importante ressaltar que o papel das universidades brasileiras sempre foi de grande relevância nas mais diversas áreas do conhecimento, e não raro foi a entrada de ex- professores nas esferas do poder político nos mais altos cargos. Em tempos não muito longínquos as universidades também se caracterizaram como um dos locais de resistência ao regime civil-militar que assolou o país por mais de duas décadas. Nesse caso, perseguições, aposentadorias compulsórias e exílio faziam parte da rotina. E do caos, muito debate, muito trabalho e muitas pautas para serem resolvidas pelas ciências humanas resultaram em ideias e livros. Obras foram publicadas, dentro do país sob o véu da censura ou no estágio do exílio. Tivemos como

*Doutorando em História Unicamp. Bolsista CNPq. 
pano de fundo diferentes problemáticas: a revolução burguesa, o sentido da colonização, a teoria da dependência, a cultura nacional ou se as ideias estavam ou não fora do lugar. Sob os mais diversos matizes a intelectualidade universitária brasileira tentou a seu modo dar conta dessa demanda, destacando-se no cenário Florestan Fernandes, Fernando Henrique Cardoso, Otávio Ianni, Celso Furtado, Raimundo Faoro, Caio Prado Jr., Sérgio Buarque de Holanda, Nelson Werneck Sodré, Antonio Cândido, Roberto Schwarz, Maria Silvia de Carvalho Franco, Carlos Guilherme Mota, para citar alguns. Relevante também é mencionar que a pósgraduação dessa época adversa apenas engatinhava.

Tamanho são os problemas levantados pelo ensaio de Jacoby que antes de adentrarmos aos muros universitários dos subúrbios estadunidenses, ele nos leva a passear pelas ruas de Greenwich Village, boêmio bairro nova-iorquino das primeiras décadas do século XX, quiçá o que significou décadas depois para a Faculdade de Filosofia da USP a rua Maria Antonia, “uma rua na contramão”, como aponta o título de um livro/documento organizado por Maria Cecília L. dos Santos, cujos personagens citados acima contribuíram com depoimentos ${ }^{1}$. Para os padrões europeus seria o mesmo que o Quartier Latin, em Paris. No auge de Village, raramente os intelectuais eram professores universitários. No geral eram escritores, polemistas, artistas, críticos que utilizavam os espaços dos jornais e periódicos como freelancers e devido aos aluguéis baratos, por lá mesmo se estabeleciam, gerando uma ampla rede de sociabilidade e um profícuo espaço de debate público tendo a rua como campo de batalha, tanto de ideias como de sobrevivência.

Das ruas de Nova York para o prefácio Jacoby se pergunta: onde estão os intelectuais? Ele busca a resposta em um livro intitulado A América e o intelectual jovem² ${ }^{2}$ de Harold Stearns (1891-1943). Este por sua vez mirava os intelectuais americanos fugidos para a Europa. Acreditava que a hostilidade de uma civilização comercial para com a juventude em geral e para com os intelectuais em particular era o que impelia os jovens escritores à Europa. Com base nessas constatações e refletindo sobre o seu presente Jacoby aponta o seguinte: “Isto não representa a situação atual. A juventude é endeusada; os intelectuais, se percebidos, são glorificados ou subsidiados. O jovem vai para a Europa não para fugir, mas de férias, às vezes para conferências. Poucos intelectuais americanos vivem no exílio. Longe de romantizar, a questão ainda permanece. Onde estão os intelectuais mais jovens? É meu ponto de partida. Eu não encontrei muitos”3.

1 SANTOS, Maria Cecília Loschiavo dos. Maria Antonia: uma rua na contramão. São Paulo: Nobel, 1988. 2 O título original da obra é America and the Young Intellectual, publicada em 1921. O título em português consta na tradução da edição do livro que apresento. 
O ensaio é dividido em sete capítulos e numa narrativa fluente Jacoby tece seu argumento sempre empenhado na tentativa de compreender como pôde haver uma lacuna tão grande entre uma geração e outra. Apresenta essa construção de sentidos através das modificações urbanas e da expansão dos campi no pós- II Guerra, locus para onde migrou a geração do baby boom ou a Nova Esquerda. Utiliza para tanto diversas categorias analíticas, tais como, boemia, intelectuais, geração, vida cultural e sem a pretensão de definí-las exaustivamente dispara contra os jargões conceituais: "excessivas definições e excessiva cautela sufocam o pensamento" ${ }^{\text {. }}$

Se no Brasil o estardalhaço não veio, talvez por motivos de preservação dos que se sentiram criticados, nos Estados Unidos ele repercutiu positivamente, ao menos é o que nos aponta o crítico Edward Said. Em uma de suas Conferências transmitidas pela rede inglesa BBC em 1993 intitulada Profissionais e Amadores, o professor de Columbia apresenta o livro de Jacoby como um trabalho que gerou grande discussão, “a maior parte dela de aprovação” 5 . Em sua fala Said reforça a apresentação da geração dos intelectuais do Village que incluíam homens e mulheres como Edmund Wilson, Jane Jacobs, Lewis Mumford e seus seguidores de um pouco mais tarde como Philip Rahv, Alfred Kazin, Susan Sontag, Daniel Bell, Lionel Trilling, pessoas que, de acordo com o autor do livro, perderam importância por causa de várias forças políticas e sociais do pós-guerra: a fuga para os subúrbios (para Jacoby o intelectual é uma criatura urbana), as irresponsabilidades da geração beat, pioneira na ideia de romper com tudo e fugir de uma posição estabelecida na vida, a expansão da universidade e a ida para o campus da primeira esquerda independente americana.

A soma desses fatores é que o intelectual hoje é muito provavelmente um professor de literatura confinado com uma renda segura, sem nenhum interesse em lidar com o mundo fora da sala de aula, indivíduos que, segundo Jacoby, "escrevem uma prosa esotérica e bizarra, dirigida principalmente para a promoção acadêmica e não para a mudança social”. E segue nas críticas: “Tudo o que nós temos agora é uma geração desaparecida que foi substituída por técnicos de sala de aula, altaneiros e impossíveis de compreender, contratados por comissões, ansiosos para agradar a vários patrocinadores e agências, eriçados com credenciais acadêmicas e com uma autoridade social que não promove debate, mas estabelece reputações e intimida os não-especialistas”.

3 JACOBY, Russell. Os últimos intelectuais: a cultura americana na era da academia. Trad. Magda Lopes. São Paulo: Trajetória Cultural: Edusp, 1990. p. 9.

4 Idem, p. 12.

5 SAID, Edward. Representações do Intelectual: as Conferências Reith de 1993. São Paulo: Companhia das Letras, 2005. p. 75.

6 Idem, p. 76-77. 
Embora concorde em parte com os temas levantados por Jacoby, Said afirma que acha errado ser injusto em relação à universidade ou mesmo aos Estados Unidos, além do que, argumenta, ser um intelectual não é de jeito algum incompatível com o trabalho acadêmico, o que concordamos. Para ele o intelectual não representa um ícone do tipo estátua, mas uma vocação individual, uma energia, uma força obstinada, abordando com uma voz empenhada e reconhecível na linguagem e na sociedade uma porção de questões, todas elas relacionadas, ao fim das contas, com uma combinação de esclarecimento e emancipação ou liberdade. E conclui: “A ameaça específica ao intelectual hoje não é a academia nem os subúrbios, nem o comercialismo estarrecedor do jornalismo e das editoras, mas antes uma atitude que chama de profissionalismo. Ou seja, o trabalho intelectual como alguma coisa que se faz para ganhar a vida entre nove da manhã e cinco da tarde, com um olho no relógio e outro no que é considerado um comportamento apropriado, profissional- não entornar o caldo, não sair dos paradigmas ou limites aceitos, tornando-se, assim, comercializável e, acima de tudo, apresentável e, portanto, não controverso, apolítico e objetivo”7 .

De volta ao livro, no primeiro capítulo Estão faltando intelectuais? Jacoby apresenta ao leitor as principais diferenças entre os intelectuais públicos e os do pós-guerra, aqueles que deixaram os centros urbanos em seus automóveis em direção aos subúrbios e lá se estabeleceram como professores universitários. Segundo o autor, “nos anos 1960, as universidades praticamente monopolizaram o trabalho intelectual; uma vida intelectual fora do campus parecia quixotesca. Quando a poeira baixou, muitos intelectuais jovens jamais haviam deixado a escola; outros descobriram que não havia nenhum outro lugar para ir. Tornaram-se sociólogos radicais, historiadores marxistas, teóricos feministas, mas não exatamente intelectuais públicos”».

O capítulo 2, intitulado O declínio da boemia apresenta o cenário intelectual em transformação. Os bares e cafés de centros como Nova York ou Chicago deixam de existir para dar lugar a especulação imobiliária e ao processo de vida nos subúrbios, a reboque do american way of life. Com isso há a construção de autoestradas e a consequente expansão universitária. O centro da cidade é agora lugar de jovens arquitetos, consultores, especialistas, executivos. As moradias boêmias deram lugar a escritórios e apartamentos caros. Conforme aponta o autor, "pensar e sonhar requerem um tempo desregulado; os intelectuais perpetuamente postados em cafés e bares ameaçam os respeitáveis cidadãos pelo esforço que colocam- ou pela aparência- em escapar da escravidão do dinheiro e do trabalho duro"9.

7 Ibidem, p. 78.

8 Idem, p. 21.

9 Ibidem, p. 41. 
O capítulo 3 parece bastante atual, na medida em que é recente a transposição de On the road, de Jack Kerouac das páginas literárias para as telas do cinema pela lente de Walter Salles. Em A caminhos dos subúrbios: urbanistas e beats, Jacoby nos mostra os anos 1950, caracterizado pela suburbanização, pela construção das autoestradas com a participação de engenheiros e arquitetos, pelo fim do macarthismo e pelos beats, personagens não romantizados e paradoxais, pois, embora fossem o embrião da contracultura da década ulterior, foram em parte também grandes propagandistas da indústria automobilística.

Se nos capítulo anteriores é apresentado o cenário, no quarto são feitas as constatações nas quais é possível vislumbrar as metamorfoses intelectuais. Em Intelectuais nova-iorquinos: judeus e outros a narrativa deixa as ruas e passa para dentro do campus da década de 1950. É o momento em que intelectuais e professores universitários se tornaram virtualmente sinônimos. O ponto alto do capítulo é o debate entre o crítico literário Lionel Trilling e o sociólogo Charles Wright Mills, representante da geração do Vilagge. Enquanto o primeiro (modelo do intelectual judeu que venceu na academia americana) celebrava o progresso cultural, o segundo lamentava o declínio e a degeneração do discurso político em slogans e comerciais de pasta de dentes. Neste exato momento, dizia Mills em 1955, “que uma oposição convincente desapareceu e os intelectuais adotam agora uma nova atitude conservadora. Em vez de criticarem a mediocridade e a estupidez, desfrutam de sua posição social recémadquirida. O sociólogo, conclui Jacoby, criticou Trilling como um dos muitos intelectuais que sucumbiram a esta confusão"10. E conclui o capítulo chamando a atenção para um problema crucial: os intelectuais nos anos 50 e 60 deixam de debater publicamente para tornarem-se uma categoria sociológica a ser problematizada.

Seguindo a narrativa do autor chegamos até a década de 1960, período do fim do macarthismo, da guerra do Vietnã e da consolidação do intelectual acadêmico, fosse ele conservador ou marxista. É a era da especialização, do jargão, da censura velada, do corporativismo e também o ponto alto da crítica de Jacoby. Assim, os capítulos 5 e 6 levam títulos complementares: A nova esquerda no campus I: a liberdade de ser acadêmico e A nova esquerda no campus II: a longa marcha nas instituições. Em ambos os capítulos, alguns pontos chamam a atenção. O autor afirma que uma revolução cultural marxista ocorreu nas universidades, porém, pacífica e democrática, realizada principalmente com livros e conferências, cujo público alvo não eram mais do que pares acadêmicos e especialistas. E as publicações pouco criticavam a guerra americana na Ásia. Tal ressalva no discurso de muitos professores, lembre-se aqui, já sinônimos de intelectuais, pode ser explicado segundo Jacoby, 10 Idem, p. 90. 
pelo medo do desemprego, receio de muitos profissionais e muito comum numa sociedade liberal como a americana.

A crítica não se estende apenas a postura profissional, cerceada pelo mercado e por padrões comportamentais, ela pega em cheio também na contribuição escrita dessa geração. O crescimento do jargão no campo da ciência política, mas não apenas nessa área, afirma Jacoby, indica não as necessidades da verdade, mas um imperialismo acadêmico, onde os professores podem reinar sobre os microcampus. O vocabulário, que a ciência política compartilha com a sociologia e os estudos internacionais, reduz o conflito humano e social a diagramas e gráficos computadorizados. A sociedade passou a ser um problema de engenharia.

Em Depois dos últimos intelectuais, último capítulo do livro, Jacoby chama a atenção, entre outros temas, para o levante conservador na tentativa de um debate público mais amplo. Se por um lado, o chamado pensamento crítico de esquerda encontrava-se escondido em escritos de pouca circulação e completamente passivos ao status quo universitário, por outro o discurso conservador se articulava em publicações com uma linguagem direta, acessível e sem rodeios. Os intelectuais conservadores eram, segundo Jacoby, os porta-vozes de grandes conglomerados empresariais, os mesmos que financiavam seus periódicos. Dessa constatação, o foco paira sobre o papel do jornalismo e das empresas de comunicação que tomaram para si a pauta dos debates públicos, antes realizada pela geração das ruas, dos bares e cafés do Village.

Jacoby conclui o capítulo reafirmando que a transformação do ambiente intelectual tradicional não é instantânea; ela é paralela ao declínio das cidades, ao crescimento dos subúrbios e à expansão das universidades, e nostalgicamente nos apresenta esse apagamento da malha urbana rebelde: "Não há necessidade de anunciar o colapso da civilização quando lanchonetes tomam o lugar de antigos restaurantes baratos, máquinas automáticas substituem bancas de jornais, ou campi verdejantes suplantam os parques vandalizados das cidades”"

Haveria muitas outras possibilidades de abordar esse ensaio. Preferi nessa breve apresentação me inserir também no hall dos criticados. O livro de Jacoby deveria ser obrigatório nos primeiros anos da vida universitária, assim quem sabe, poderia salvar do pedantismo centenas de jovens promissores ávidos pelo uso de jargões e pela produtividade acelerada e especializada de artigos ou papers que pouco serão lidos. Se limitado a uma temporalidade e a uma espacialidade que não a nossa, o ensaio pode servir, por outro lado, de provocação aos nossos intelectuais. Onde eles estão?

11 Ibidem, 245. 
As pautas montadas pela academia durante os anos 60 e 70 no Brasil censura que promovia debates acalorados como afirmado no início, pelo visto agora no Brasil, um país de todos, estão dadas pelos editoriais das empresas de comunicação. Os poucos intelectuais que vejo na arena pública constituem-se porta-vozes ideológicos da chamada grande imprensa ${ }^{12}$. Outros encontram-se no governo. Vozes e mãos autorizadas de especialistas, consultores, jornalistas que opinam sobre tudo e sobre todos. Onde está o contraponto? Ao que tudo indica e pelas pistas apresentadas por Jacoby continuam nos campi, como deve ser: sem voz, sem espaço e sem vez. Por que? Sem generalizar, porque hoje talvez só lembrem dos embates em momentos específicos como a greve que ora mobilizam. Passada a tempestade, voltam imunes ao conforto de seus departamentos, laboratórios e publicações. Trabalharão novamente entre pares. Ou lembrarão de nós, do lado de fora, quando reivindicarem um novo reajuste.

Brasília, 29 de agosto de 2012.

12 Exemplo claro do que estou levantando como crítica pode ser visto no sítio do Instituto Millenium http://www.imil.org.br/. Basta uma olhada rápida para desvendar as redes de sustentação do discurso liberal de seus articulistas, compostas pelas principais empresas de comunicação do país. 